\title{
A Case of Lobular Capillary Hemangioma at the False Vocal Cord With Intermittent Stridor
}

\author{
Sang-Wook Park ${ }^{(D)}$, Ki Ju Cho ${ }^{1,2}$ (D), Seongjun Won ${ }^{1,2}$ (D), and Jung Je Park ${ }^{1,2}$ (D) \\ 'Department of Otorhinolaryngology, Gyeongsang National University School of Medicine, Jinju, Korea \\ ${ }^{2}$ Institute of Health Sciences, Gyeongsang National University, Jinju, Korea
}

Lobular capillary hemangioma (LCH) is a type of benign vascular tumor. It arises from vascular endothelial cells and contains capillaries arranged in a lobular pattern. In the head and neck, the most common presenting location of LCH is the lips, and presentation in the larynx is very rare. $\mathrm{LCH}$ might not be distinct from granuloma in macroscopic views. We report a 71-year-old female with $\mathrm{LCH}$ of the larynx that was totally resected via laryngeal microsurgery with a $\mathrm{CO}_{2}$ laser and briefly review the literature.

Keywords Hemangioma, lobular capillary; False vocal cord; Granuloma, pyogenic.

\section{INTRODUCTION}

Lobular capillary hemangioma $(\mathrm{LCH})$ is a common vascular-proliferative tumor in the skin and oral mucosa, but rarely occurs in the larynx [1]. It was previously called pyogenic granuloma because it is reddish and nodular and is difficult to distinguish from laryngeal granuloma [2]. LCH is associated with trauma, pregnancy, and hormonal changes, but the cause has not been clearly identified [3]. It can occur in any age and sex group, but is predominant in young female adults, possibly due to hormonal effects on vessels [4]. LCH can cause various symptoms, such as hoarseness, throat discomfort, and dyspnea, as the mass grows [5]. We report the rare case of a 71-year-old female patient with LCH in the false vocal cord who was treated successfully without complications and briefly review the literature.

\section{CASE REPORT}

A 71-year-old female visited our clinic for throat discomfort, hoarseness, and intermittent stridor, which had lasted for 3 months. She did not complain of other symptoms such as cough, sputum, hemoptysis, and dyspnea. Her social history was unremarkable. She was a non-smoker and had no history of alcohol drinking. She also denied experience of voice abuse. She had twice received general anesthesia and received regular check-ups for essential hypertension. Laryngoscopic examination found a reddish, smooth surfaced, pedunculated, mass-like lesion at the left false vocal cord. Vocal cord motility was intact and aryepiglottic cartilage movement was clear (Fig. 1). Preoperative computed tomography revealed a well-enhanced, solid, and nodular tumor measuring $0.6 \mathrm{~cm}$ at the left false vocal cord (Fig. 2). We suspected it was a hemangioma or contact granuloma based on her medical history and endoscopic findings. The patient wished to undergo surgical removal; therefore,

\author{
Received August 29, 2021 \\ Revised October 12, 2021 \\ Accepted October 13, 2021 \\ Corresponding Author \\ Jung Je Park, MD, PhD \\ Department of Otorhinolaryngology, \\ Gyeongsang National University Hospital, \\ 79 Gangnam-ro, Jinju 52727, Korea \\ Tel +82-55-750-8177 \\ Fax+82-55-759-0613 \\ E-mail capetown@hanmail.net

\section{ORCID iDs} \\ Sang-Wook Park iD \\ https://orcid.org/0000-0002-7579-2327 \\ Ki Ju Cho (iD) \\ https://orcid.org/0000-0002-1414-6655 \\ Seongjun Won (iD \\ https://orcid.org/0000-0003-4163-4053 \\ Jung Je Park (D) \\ https://orcid.org/0000-0001-6325-0398 \\ This is an Open Access article distributed \\ under the terms of the Creative \\ Commons Attribution Non-Commercial \\ License (https://creativecommons.org/ \\ licenses/by-nc/4.0) which permits \\ unrestricted non-commercial use, \\ distribution, and reproduction in any \\ medium, provided the original work is \\ properly cited.
}




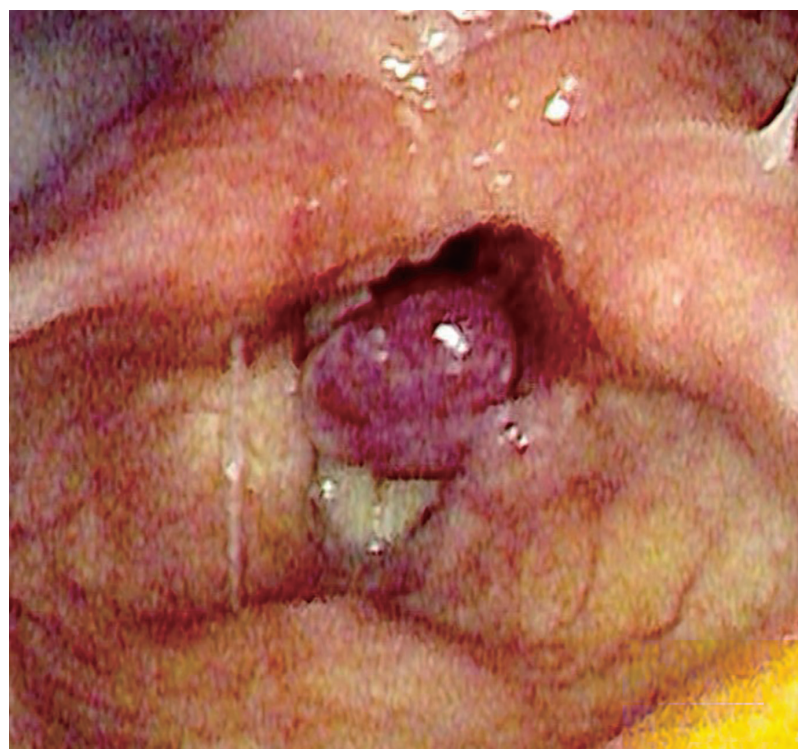

Fig. 1. Preoperative laryngoscopic image showing a pedunculated, mass-like lesion at the left false vocal cord. we planned to perform suspension laryngoscopic excision of the mass using a $\mathrm{CO}_{2}$ laser.

We carefully inserted a $5.5-\mathrm{cm}$-sized orotracheal intubation tube using video assisted technique to avoid disrupting the operation field. We prepared a $\mathrm{CO}_{2}$ laser, a suction bovie, and coagulation forceps to manage involuntary bleeding. The mass was pedunculated; therefore, we dissected the neck at the origin site using a $\mathrm{CO}_{2}$ laser set to continuous superpulse mode of $2 \mathrm{~W}$. A vessel, suspected to be the feeding vessel, at the origin site was coagulated using coagulation forceps, and then the mass lesion was completely resected from the false vocal cord. There was no visible remarkable bleeding event or mucosal injury near the resection site. The mass was confined to the left false vocal cord. LCH was confirmed by pathology because the mass exhibited lobular formation of proliferative blood vessels of various sizes (Fig. 3). At 3 months after surgery, the patient is well and free of disease without any complaints (Fig. 4).
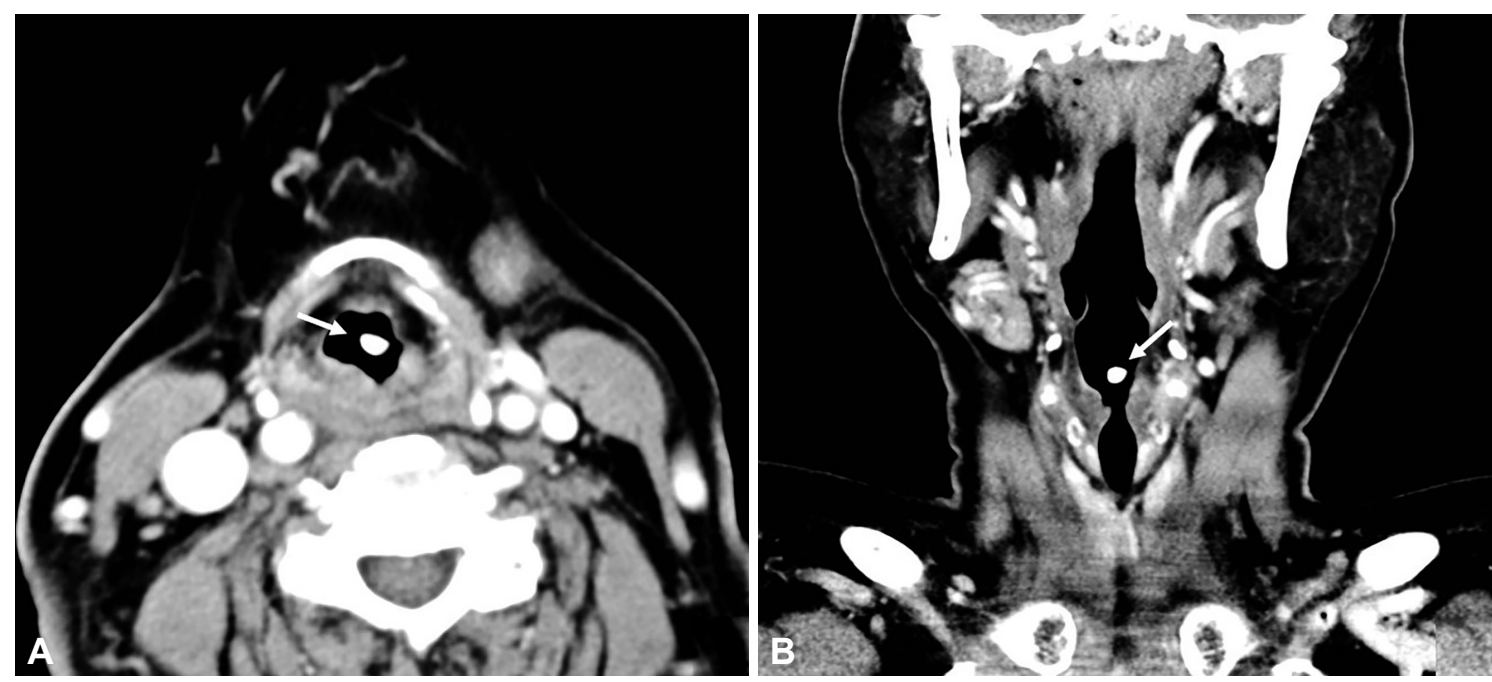

Fig. 2. Representative preoperative computed tomography scans (A: axial view, B: coronal view) of the well-enhanced, nodular lesion measuring $0.6 \mathrm{~cm}$ at the larynx (arrows).
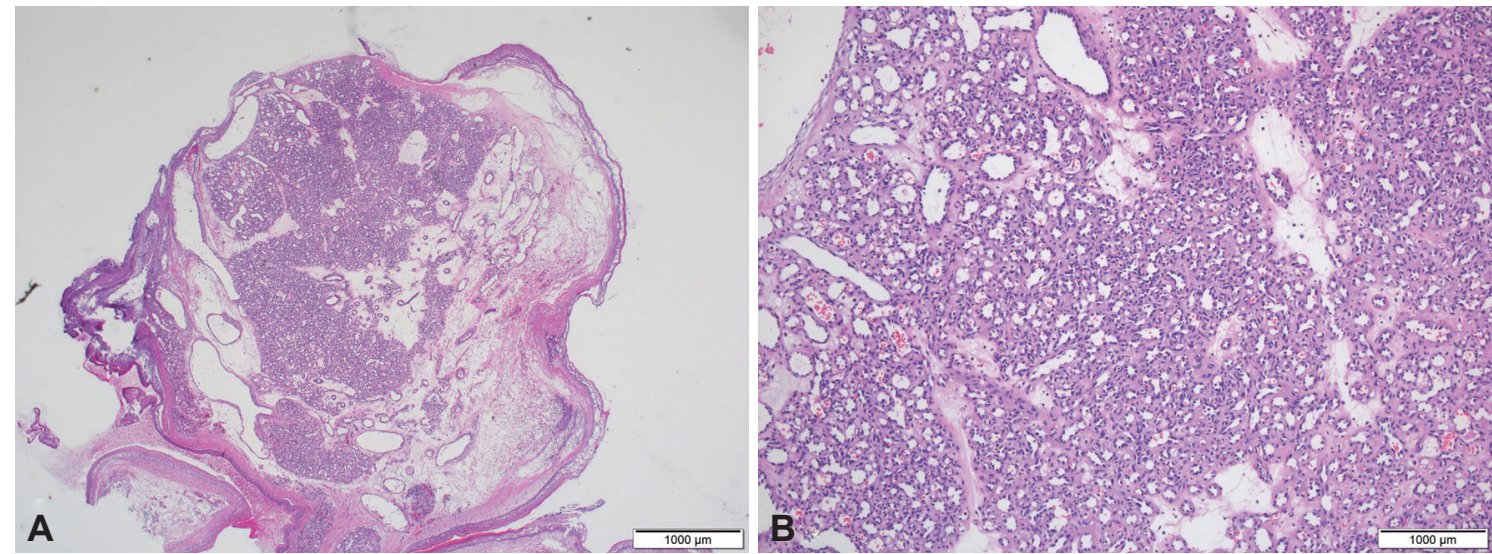

Fig. 3. Microscopic findings of the lesion. Proliferative blood vessels of various sizes with a lobular formation $(H \& E, A: \times 40, B: \times 100)$. 


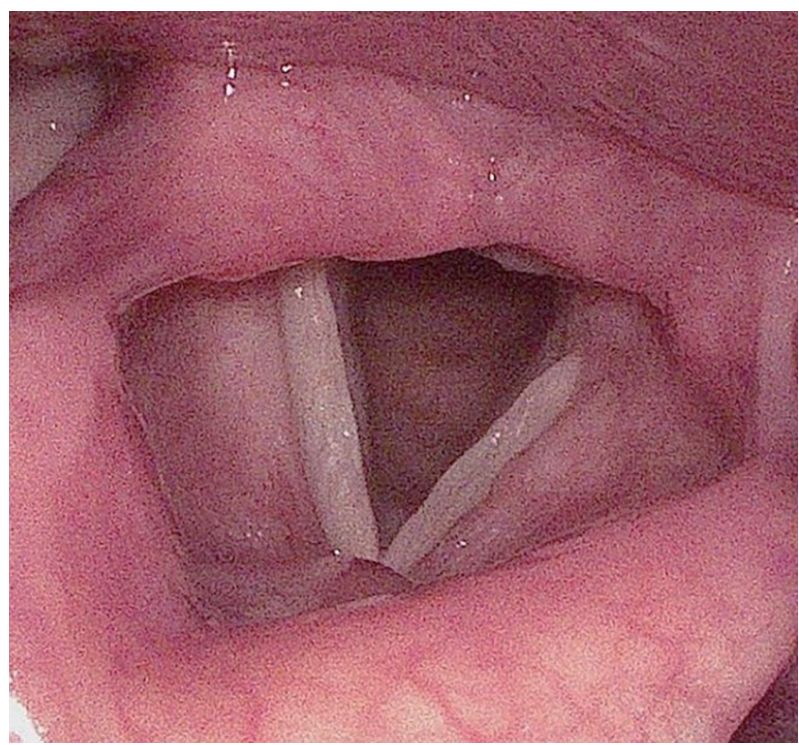

Fig. 4. Laryngoscopic image at 3 months postoperatively showing no visible mass-like lesion.

\section{DISCUSSION}

$\mathrm{LCH}$, also known as pyogenic granuloma, is a benign vascular-proliferative tumor in the skin and oral mucosa [1]. The term 'pyogenic granuloma' is a pathologic misnomer because the lesion is not induced by bacterial infection and is not a granuloma. This term was introduced by Hartzell in 1904 [3]. In 1981, Fechner et al. [6] reviewed histological findings and corrected it to LCH because such masses show distinct lobular proliferation of capillaries rather than general granulomas.

Although the pathogenesis of LCH has not been clearly elucidated, it is believed to be related to trauma, hormonal changes, microscopic arteriovenous malformation, and effects of abnormal vascular endothelial growth factor [3]. Almost one-third of LCHs are located in the head and neck region [1]. It occurs frequently on the skin and oral mucosa, but rarely in the larynx (1\%-2\%) [7]. Among LCH occurring in the larynx, it has been reported several times in the true vocal cords, which contact frequently due to vocalization, but has not previously been reported in the false vocal cord.

LCH is a dark red, pedunculated mass that is easily pressed. It is difficult to distinguish from a granuloma with the naked eye [3]. Symptoms can include throat discomfort and hoarseness depending on the location, size, and shape of the mass. Bleeding at the lesion can cause hemoptysis, and dyspnea is also possible if the lesion is large enough to block the airway. Management of LCH depends on the severity of symptoms [5]. If the lesion is small and does not cause symptoms, clinical observation is possible $[4,8]$. However, if the lesion causes symptoms and conservative therapy has no effect, surgical resection is the optimal treatment choice [2,4].

Complete surgical resection should be performed to prevent recurrence of LCH. Surgeons must prepare for massive bleeding, which can disrupt the operation field. After resection, aspiration or a large hematoma can occur in a short period of time; therefore, complete hemostasis and careful observation are required before the operation is completed.

We reported a LCH that could be mistaken for a granuloma in the larynx and briefly reviewed the literature.

\section{Acknowledgments}

None

\section{Conflicts of Interest}

The authors have no financial conflicts of interest.

\section{Authors' Contribution}

Conceptualization: Jung Je Park. Data curation: Sang-Wook Park. Investigation: Sang-Wook Park, Ki Ju Cho, Seongjun Won. Methodology: Jung Je Park. Project administration: all authors. Resources: Jung Je Park. Supervision: Jung Je Park, Ki Ju Cho, Seongjun Won. Writing-original draft: Sang-Wook Park. Writing-review \& editing: Jung Je Park. Approval of final manuscript: all authors.

\section{REFERENCES}

1. Giblin AV, Clover AJ, Athanassopoulos A, Budny PG. Pyogenic granuloma - the quest for optimum treatment: Audit of treatment of 408 cases. J Plast Reconstr Aesthet Surg 2007;60(9):1030-5.

2. Lee HJ, Lee GJ. A case of pyogenic granuloma in larynx. J Korean Soc Laryngol Phoniatr Logoped 2019;30(1):69-71.

3. Kang YS, Kang Y, Han DH. A case of 2-month-old infant with lobular capillary hemangioma. J Rhinol 2017;24(2):127-31.

4. Jafarzadeh H, Sanatkhani M, Mohtasham N. Oral pyogenic granuloma: A review. J Oral Sci 2006;48(4):167-75.

5. Ko JS, Park HW, Kim JP, Woo SH. One case report of obstructing pyogenic granuloma. J Korean Soc Laryngol Phoniatr Logoped 2010; 21(2):139-41.

6. Fechner RE, Cooper PH, Mills SE. Pyogenic granuloma of the larynx and trachea. A causal and pathologic misnomer for granulation tissue. Arch Otolaryngol 1981;107(1):30-2.

7. Garrett MM, Lee WT. Obstructing pyogenic granuloma as a result of blunt laryngeal trauma. Otolaryngol Head Neck Surg 2007;136(3): 489-90.

8. Hanick AL, Meleca JB, Billings SD, Bryson PC. Pyogenic granuloma of the larynx: A rare cause of hemoptysis. Am J Otolaryngol 2019; 40(2):331-3. 